\title{
Determinants of Investment Decisions among Pensioners at Kabarak University, Kenya
}

\author{
Joseph Maina Gichuki ${ }^{1}$, Prof. Nemwel Bosire ${ }^{2}$, Antony Wahome ${ }^{3}$ \\ ${ }^{I}$ MBA Candidate, Jomo Kenyatta University of Agriculture and Technology. Email: \\ ${ }^{2}$ Senior Lecturer, Jomo Kenyatta University of Agriculture and Technology \\ ${ }^{3}$ Lecturer, Jomo Kenyatta University of Agriculture and Technology
}

\begin{abstract}
Pensions funds are the principal sources of retirement income for millions of people in the world. The need for re-investing one's retirement savings to improve the level of income of pensioners is an important issue facing the contemporary society more so among retirees without a sound investment plan or financial literacy to back their investment activities. This study thus, sought to assess the determinants of investment decisions for pensioners in institutions of higher learning in Kenya. The objectives of the study were; to determine how income levels influence investment decisions by pensioners in institutions of higher learning; to investigate how financial literacy influences investment decisions by pensioners in institutions of higher learning; to establish how retirement age influences investment decisions made by pensioners in institutions of higher learning. The study was based on three major theories; life cycle savings theory, The Bequest theory and Precautionary Motives Theory. The study used a descriptive research design with a target population of 302 pensioners. The study used stratified sampling technique to select a representative sample of 76 pensioners. A census collected all information about every member of the sample population. The actual research data was then collected, cleaned and then analyzed using SPSS version 20. The study conducted both a descriptive analysis and an inferential analysis to explain the relationships between the independent variables and the dependent variable. A Pearson correlation analysis was done to show the relationships between the variables and the findings presented in tables. There was a statistically significant strong positive correlation between financial literacy of $.299(p=0.07<0.01)$ and investment decisions by pensioner in Kabarak University. The study found statistically significant weak positive correlation coefficient between Investment opportunities of $.043(p=.366<0.01)$ and investment decisions by pensioner in Kabarak University. The study concludes that investment decisions have influenced investments made by pensioners at Kabarak University. The study recommended that it is necessary to undertake savings and investments in projects that present better returns with guarantee for payoffs. It was recommended that further studies should be done so as to assess implications of these determinants on the effectiveness of the choice of investment decisions made by the pensioners.
\end{abstract}

\section{Introduction}

A good pension scheme does not only serve as an incentive to employees but helps to attract and retain experienced staff. Occupational Pensions Regulatory Authority (OPRA, 2016). Going by the statistics, only fifteen percent of the world's 6.6 billion people, Kenya included have access to any form of formal system of retirement income support. This is exacerbated by the rapidly degenerating traditional social fabric safety net for old age, where children took care of the old, fueled by changes in social behavior brought about by rural to urban migration, modernization and civilization. Further, government willingness to fund social security obligations, that continue to rise relative to revenues, is declining. As a result, parametric measures such as increasing retirement ages, and conversion of government only sponsored schemes to contributory schemes are being implemented to delegate the social security burden back to the citizens.

All these put together and in the absence of any intervention, it is eminent that the majority of the world's population is significantly exposed to the risk of old age poverty. According to the International Labor Organization (ILO), about 80 per cent of the world's population has no access to formal security beyond the possibilities presented by informal networks such as family, kingship groups or communities. Four out of every five people in the world live in conditions of social insecurity. This proportion is even higher in countries of sub-Saharan Africa where more than 90 per cent of the population are generally not covered under any social security scheme. In Kenya existing schemes are limited to formal sector workers. The ILO estimates that 'about 84 per cent of labor force is excluded, while many of those who are covered receive benefits that fall short of their basic needs.

In Kenya, the number of Defined Contribution schemes with 5,000 or more members has increased by 50\% since December 2013. At the same time, the data shows that the majority of Defined Contribution schemes have now closed to new members. Concentration of memberships is in larger schemes, noting that $86 \%-5.9$ million - of savers are now in 120 schemes with 5,000 or more members. 


\section{Statement of the Problem}

One of the primary motivations for the establishment of a retirement benefits schemes is to provide for members in their old age. It is also meant to provide retirees with a certain standard of living so as to ensure that their income does not fall below a certain minimum level after retirement. However, many retirees suffer during their retirement due to lack of sufficient income to finance their needs. In Kenya, the income replacement ratio falls way below the ILO recommended standard of 40 percent (Government of Kenya, 2008). This is further complicated by the fact that the old have special and different needs, including health care compared to the younger generation. The need for re-investing retirement savings to improve the pensioners' income is critical to many retirees, especially those without financial literacy to back their investment decisions. The number of pension funds and membership in Kenya have grown significantly, however studies carried out on the same have not covered in depth the factors that affect investment decisions by pensioners hence the need for the study. There are also concerns on imprudent asset management in pension schemes (Nyakundi, 2006) thus the need for the study to establish the drivers of investment decisions among pensioners in Kenya by analaysing the case of Kabarak University Pension Scheme.

\section{Objectives}

- To determine how income levels influence investment decisions by pensioners in Kabarak University

- To investigate how financial literacy influences investment decisions by pensioners in Kabarak University

- To establish how retirement age influences investment decisions made by pensioners in Kabarak University

\section{Brief Literature Review}

Studies done in the past indicate that people pursue varied investments to secure better future for themselves and probably their dependants. According to Islamoglu, Apan, \& Ayvali (2015), the probability of profit and loss in the investment process makes decision-making difficult for individuals. For example, Islamoglu, Apan, \& Ayvali (2015) observe that investors are of the view that they can increase or decrease investment risks by increasing the size of their investment portfolios despite the fact that investment risks cannot be reduced just by using savings to increase the number of investment options in a given portfolio. In this scope, the rational use of savings is determined by how quickly and efficiently information about investment.

As Starcek, \& Trunk, (2013) opine, having a good command of financial literacy enables people to develop skills they need to manage finances and enhance their welfare. It also makes individuals good at making rational financial decisions. Financial literacy covers basic literacy, reading, arithmetic and requires more knowledge and skills in the financial field. It entails acquisition of information about finances, financial trends and the ability to understand the financial products, notions and risks (Huston, 2010).

Recent literature in the field of economics as documented by Lusardi \& Mitchell (2014) correlate financial literacy with certain economic behaviours. The study argues that lack of basic financial knowledge may lead to individuals using crude rules of the thumb in financial decision making and choice of investment options. In fact, poorer, less educated persons are typical cases of low or no financial literacy who often make financial errors.

According to Zandberg (2010) retirement age also plays a role in pensioners' investment decisions whereby there are different sectors of employment; the formal and informal sectors. A study conducted by Gamble, Boyle, Yu, \& Bennet (2015) on how aging affects financial decision making confirm that financial decision making is largely affected by declining cognition. However, the study indicates that aging has little effect on the investment decisions people make.

\section{Research Methodology}

Research Design: Descriptive survey design was used in preliminary and exploratory studies to allow researchers to gather information, summarize, present and interpret for the purpose of clarification. The choice of the descriptive survey research design was guided by the fact that no variable would be manipulated. This study therefore, was able to generalise the findings to a larger population.

Target Population: The target population consisted of 76 pension members as per Kabarak University's HR department 2016. A census design was used to collect information about every member of the population

\section{Data Collection Instrument:}

The researcher used structured questionnaires as the instrument of data collection. The selection of these tools were guided by the nature of data to be collected, time available and the objectives of the study. To guarantee validity, the researcher conducted a face and content validity test on the measuring instrument, and had the test reviewed by experts and obtained feedback. To ensure reliability of the measuring instrument a 
Cronbach alpha $(\alpha)$ with a reliability threshold of $(\alpha \geq 0.7)$ was used to test the internal consistency of the questionnaire.

\section{Data Processing and Analysis}

The analysis used a combination of various techniques of data analysis to determine an overall picture of the study variables. A range of descriptive statistical measures used included the mean, frequencies and standard deviation. In addition, tables were also used exclusively to present the findings. Pearson correlation analyses was used to determine the influence of various factors on investment decision-making.

Findings: The findings are presented based on the research objectives:

Income Levels: The Table 1 presents the descriptive statistics on the responses on the income levels and investment decision among pensioners.

Table 1: Descriptive statistics for income levels

\begin{tabular}{|c|c|c|c|c|c|}
\hline & $\mathrm{N}$ & Min & Max & Mean & Std. Dev \\
\hline Income from pension influences the Investment decisions & 66 & 0 & 5 & 4.11 & 1.040 \\
\hline The amount received as pension affects the Investment decisions made & 66 & 0 & 5 & 4.09 & 1.186 \\
\hline The level of savings is directly linked to the level of investment by pensioners & 66 & 0 & 5 & 3.74 & 1.385 \\
\hline The number of dependants on pension income affects the investment decisions & 66 & 0 & 5 & 4.18 & .910 \\
\hline Pension income supplements incomes at old age & 66 & 0 & 5 & 4.23 & .873 \\
\hline
\end{tabular}

According to the study findings, the surveyed respondents agreed (mean $=4.11 ;$ std dev $=1.040)$ that income from pension influences the investment decisions and also agreed (mean $=4.09$; std $\operatorname{dev}=1.186$ ) that the The amount received as pension affects the investment decisions the pension members make. However, there was divided opinion as some respondents agreed while others disagreed (mean $=3.74$; std dev $=1.385$ ) that the level of savings directly relates to the level of investment by pensioners. Besides, majority of the respondents also agreed (mean $=4.18$; std dev $=0.91$ ) that the number of dependants on pension income affects their investment decisions and also agreed (mean $=4.23$; std dev $=0.873$ ) that the pension income supplements incomes at old age.

Financial Literacy: In tandem with the second objective, this study also sought to find out the effect of financial literacy on investment decisions by pension members. The results of the descriptive analysis are shown in Table 2.

Table 2: Descriptive Statistics for Financial Literacy

\begin{tabular}{|c|c|c|c|c|c|}
\hline & $\mathrm{N}$ & Min & Max & Mean & Std. Dev \\
\hline Financial literacy impacts on investment decisions & 66 & 4 & 5 & 4.49 & .332 \\
\hline Adequate financial knowledge helps pensioners to make sound investment decisions & 66 & 3 & 5 & 4.47 & .588 \\
\hline Financial advisors assist pensioners to make better choices of investments & 66 & 2 & 5 & 4.52 & .707 \\
\hline The level of education determines the soundness of investment decision & 66 & 4 & 5 & 4.59 & .495 \\
\hline Financial literacy is key in regard to investments decisions for a pensioner & 66 & 3 & 5 & 4.64 & .572 \\
\hline
\end{tabular}

Going by the study findings, it was strongly agreed (mean $=4.49$; std dev $=0.332)$ that the Financial literacy impacts on investment decisions. The respondents also agreed (mean $=4.47$; $\mathrm{std} \mathrm{dev}=0.588$ ) that adequate financial knowledge helps pensioners to make sound investment decisions. The respondents strongly agreed (mean $=4.52$; std dev $=0.707$ ) that financial advisors play a critical role in assisting pensioners to make better choices of investments. The study findings further indicated (mean $=4.36$; std $\operatorname{dev}=0.715$ ) that investments decisions by pensioners are linked to the level of financial advisors' expertise and the respondents strongly agreed $($ mean $=4.59$; std $\operatorname{dev}=0.495)$ that the level of education determines the soundness of investment decision.

\section{Retirement Age}

In tandem with the third objective, this study also sought to find out the perceptions held by the respondents regarding the influence of retirement age on investment decisions by the pension members. The results of the descriptive analysis are shown in Table 3

Table 3: Descriptive Statistics for Retirement Age

\begin{tabular}{|c|c|c|c|c|c|}
\hline & $\mathrm{N}$ & Min & Max & Mean & Std. Dev \\
\hline Retirement age influences investment decisions & 66 & 3 & 5 & 4.45 & .416 \\
\hline The nature of investment decisions by pensioners is determined by retirement age & 66 & 3 & 5 & 4.32 & .612 \\
\hline Government regulations on retirement age can affect investment decisions & 66 & 3 & 5 & 4.52 & .685 \\
\hline The number of years spent in a sector may determine the investments made by a & 66 & 3 & 5 & 4.36 & .715 \\
\hline
\end{tabular}


Determinants of Investment Decisions among Pensioners at Kabarak University, Kenya

\begin{tabular}{|c|c|c|c|c|c|}
\hline ensioner & & & & & \\
\hline Early retirement presents a better opportunity for investment & 66 & 3 & 5 & 4.53 & .684 \\
\hline
\end{tabular}

The findings of the study show that respondents strongly agreed (mean $=4.45$; std dev $=0.416$ ) that retirement age influences investment decisions and also agreed (mean $=4.32$; std dev $=0.612$ ) that the nature of investment decisions made by pensioners is determined by retirement age. It was also observed (mean $=4.52$; std $\operatorname{dev}=0.685$ ) that the respondents strongly agreed that the government regulations on retirement age affects investment decisions and also agreed (mean $=4.36$; std dev $=0.715$ ) that the number of years spent in a sector may as well influence the choice of investments made by a pensioner. It was also strongly agreed (mean $=4.53$; std $\operatorname{dev}=0.684$ ) that early retirement presents a better opportunity for investment and that choice of retirement scheme impacts the members' investment decisions.

Investment Decisions: This study also sought to find out the perceptions held by the respondents regarding Investment Decisions. The results of the descriptive analysis are shown in Table 4.

Table 4: Descriptive Statistics for Investment Decisions

\begin{tabular}{|l|l|l|l|l|l|}
\hline & N & Min & Max & Mean & Std. Dev \\
\hline Capacity of Investment increases when the value of pension increases & 66 & 4 & 5 & 4.46 & .396 \\
\hline $\begin{array}{l}\text { Access to long-term funds is a constraining factor to the growth of } \\
\text { investment portfolio }\end{array}$ & 66 & 3 & 5 & 4.32 & .612 \\
\hline Low level of incomes and credit risk constrain investment acquisition & 66 & 3 & 5 & 4.52 & .685 \\
\hline $\begin{array}{l}\text { Pension attracts new employees since in to guarantees good life after } \\
\text { retirement }\end{array}$ & 66 & 3 & 5 & 4.36 & .715 \\
\hline
\end{tabular}

Going by the study findings shown in Table 4 , it was observed (mean $=4.46$; std dev $=0.396$ ) that capacity for investment increases when the value of pension increases. The findings also indicated that the respondents agreed (mean $=4.32$; std dev $=0.612$ ) that access to long-term funds is a constraining factor to the growth of pensioners' investment portfolio and also agreed strongly (mean $=4.52$; std dev $=0.685$ ) that Low level of incomes and credit risk constrain investment acquisition. In addition, a majority of the respondents agreed (mean $=4.36$; std dev $=0.715$ ) that pension schemes attract new employees since in to guarantees good life after retirement.

Correlation Analysis: Parson correlation analysis was used to determine the relationship between the determinanats and investment decisions.

\section{Relationship between Income Levels and Investment Decisions}

This section outlines the results of a correlation analysis between income levels and investment decisions. The findings are interpreted and further discussed accordingly.

Table 5: Correlation between income levels and investment decisions

\begin{tabular}{|l|l|l|}
\hline \multirow{2}{*}{ Income Levels } & Correlation Coefficient & .014 \\
\cline { 3 - 3 } & Sig. (1-tailed) & .455 \\
\cline { 3 - 3 } & $\mathrm{N}$ & 66 \\
\hline
\end{tabular}

**. Correlation is significant at the 0.01 level (1-tailed).

The study revealed (Table 5) that the relationship between Income Levels and Investment Decisions was weak and statistically insignificant $(r=0.014 ; p>0.01)$. The study observed that the income levels of the pensioners do not significantly influence the investment decisions they make

\section{Relationship between Retirement Age and Investment Decision}

This section outlines the results of a correlation analysis between retirement age and investment decisions made by the pensioners (Table 6). The findings are interpreted and hence discussed accordingly.

Table 6: Correlation between retirement age and investment decision

\begin{tabular}{|l|l|l|}
\hline \multirow{2}{*}{ Retirement Age } & Correlation Coefficient & Investment Decision \\
\cline { 3 - 3 } & Sig. (2-tailed) & $.904^{* *}$ \\
\cline { 3 - 3 } & $\mathrm{N}$ & 600 \\
\hline
\end{tabular}

**. Correlation is significant at the 0.01 level (2-tailed).

The study findings showed (Table 6) that the relationship between retirement age and investment decisions was positive, strong and statistically significant $(r=0.904 ; p<0.01)$. The findings of the study 
implied that the investment decisions made by the retirees depend on their age as at the time they get the pension money.

\section{Relationship between Financial Literacy and Investment Decision}

This section outlines the results of a correlation analysis between financial literacy and investment decisions made by the pensioners (Table 7). The findings are interpreted and hence discussed accordingly.

Table 7: Correlation between financial literacy and investment decision

\begin{tabular}{|l|l|l|l|}
\hline \multicolumn{2}{|l|}{ Financial Literacy } & Correlation Coefficient & $.299^{* *}$ \\
\cline { 3 - 4 } & Sig. (2-tailed) & .007 \\
\cline { 3 - 3 } & $\mathrm{N}$ & 66 \\
\hline
\end{tabular}

**. Correlation is significant at the 0.01 level (2-tailed).

The study findings showed (Table 7) that the relationship between financial literacy and investment decisions was positive, strong and statistically significant $(r=0.299 ; \mathrm{p}<0.01)$. The findings of the study implied that the investment decisions made by the retirees are determined by their financial literacy levels.

\section{Discussion}

Based on the study findings, the surveyed pensioners indicated, on average, that the income due from pension influences their choice of investment options and decisions. The study findings further indicated that the amount of money received as pension determines the investment decisions they make. The study also indicated that the level of savings by the employees under the pension scheme is directly linked to their respective levels of investment. According to the study, the number of persons depending on the employees' pension income affects the investment decisions and that the pension income earned by the pensioners after retirement supplements incomes at old age.

The findings of the study show that respondents agreed that retirement age influences investment decisions and also agreed that the nature of investment decisions made by pensioners is determined by the retirement age. It was also observed that the respondents concurred that the government regulations on retirement age affect investment decisions. The study also established that the number of years the employees spent in a sector may as well influence their choice of investments upon attaining the retirement age. It was also observed that the option to take early retirement presents a better opportunity for the pension beneficiaries to invest and that the choice of retirement scheme impacts the members' investment decisions.

Going by the study findings, the surveyed respondents indicated that the level of financial literacy impacts the investment choices and decisions made by the investors. The study further shows that possession of adequate financial knowledge helps pensioners to make sound investment decisions. The respondents also pointed out that the beneficiaries of pension rely greatly on financial advisors who assist the pensioners to make better choices of investments. The study findings further indicated that the investment decisions made by pensioners are linked to the extent and level of financial advisors' expertise and education both which determine the soundness of investment advice and decision taken.

\section{Conclusions}

The study revealed that the relationship between Income Levels and Investment Decisions was weak and statistically insignificant. This implied that one's propensity to invest does not necessarily have to be driven by higher income earnings, but rather pursuit of certain objectives that can be personal. The study also observed that the income levels of the pensioners do not significantly influence the investment decisions they make because investment decisions are also influenced by several other factors.

The study findings showed that the relationship between the age at which a person retires and investment decisions they make was positive, strong and statistically significant implying that the investment decisions made by the retirees depend on their age as at the time they get the pension money. Individuals who opt to take early retirement may pursue investment options that other older colleagues may not like. Also, the age at which a person joins productive and active employment determines the king of Investments such a person may prefer.

The study further indicated that the relationship between financial literacy and investment decisions was positive, strong and statistically significant. The findings of the study implied that the investment decisions made by the retirees are determined by their financial literacy levels. This implied that more financially informed and enlightened employees are capable of making sound investment decisions that are well calculated as opposed to those lacking financial literacy whose investment decisions may not be backed by any command of financial knowledge. 


\section{Recommendations}

The recommendations made in this study were based on the study findings in relation to the existing literature. According to the findings presented in the previous chapter, the following recommendations were imperative: first, there is need for the pension schemes to invest more in technology and other infrastructure so as to enhance service delivery and eliminate unnecessary costs. Secondly, it is necessary to undertake savings and investments in projects that present better returns with guarantee for payoffs.

\section{References}

[1]. Gamble, K. J., Boyle, P. A., Yu, B. L., \& Bennett, D. A. (2015). How Does Aging Affect Financial Decision Making. Center for Retirement Research at Boston College. 15(1), 1-7.

[2]. Huston, S., J. (2010). Measuring Financial Literacy. The Journal of Consumer Affairs, vol. 44(2), pp. 296-317.

[3]. Islamoglu, M., Apan, M., \& Ayvali, A. (2015). Determination of Factors Affecting Individual Investor Behaviours: A Study on Bankers. International Journal of Economics and Financial Issues. 5(2), 531-543.

[4]. Lusardi, A., \& Mitchell, O. S. (2014). The Economic Importance of Financial Literacy: Theory and Evidence. Journal of Economic Literature, vo. 52(1), pp. 4-44.

[5]. Nyakundi D. B (2006), Problems Facing Kenya's Pension System: A case for reforms of Laws Relating to pensions, Nairobi; UoN

[6]. Occupational Pension Regulatory Authority press release 26, January 2016

[7]. Starcek, S., \& Trunk, A. (2013). The Meaning and Concept of Financial Education in the Society of Economic Changes. International Conference 2013; Active Citizenship by Knowledge Management \& Innovation, (pp. 1443-1452). Zadar, Croatia

[8]. Zandberg, E and Spierdijk (2010) Funding of Pensions and Economic Growth: Are they Really Related? Discussion Paper N0 12/2010-082, Netspar 